\title{
What is learned during place preference conditioning? A comparison of food-and morphine-induced reward
}

\author{
THIERRY SPITERI and GILLES LE PAPE \\ Université de Tours, Tours, France \\ and \\ ANDERS ÅGMO \\ University of Troms $\emptyset$, Tromsø, Norway
}

\begin{abstract}
Mice were subjected to place preference conditioning using either morphine ( $3 \mathrm{mg} / \mathrm{kg}$ ) or food as reward. During conditioning and test, detailed observations of the animals' behavior were made. Both morphine and food produced place preference. In the animals rewarded with morphine, this was due to longer visits to the rewarded compartment, whereas food-rewarded mice made more frequent visits of the same length as before conditioning. The frequency with which the different behavioral items were displayed was subjected to factorial analyses of correspondence. These analyses showed that morphine and food reward had different behavioral consequences. At test, the animals rewarded with morphine remained in close contact to environmental cues that had been associated with morphine administration. This was interpreted as showing that these cues had been associated with a morphineinduced affective reaction. To the contrary, food-rewarded animals displayed a lot of exploratory behaviors, like rearing and sniffing, indicating that they were searching for the now-absent food in the environment where it had previously been present. Thus, while morphine-induced place preference is a result of associations between an affective state and environmental stimuli, food-induced preference is based on conditioned approach behaviors, and affective reactions are only of marginal importance for conditioning.
\end{abstract}

Place preference conditioning is a procedure originally developed for the study of affective consequences of drugs (Rossi \& Reid, 1976). It has been widely used during the last 20 years (Schechter \& Calcagnetti, 1998; Tzschentke, 1998), and in addition to drugs many natural rewards have been studied. These include among others food (Perks \& Clifton, 1997; Spyraki, Fibiger, \& Phillips, 1982), water (Crowder \& Hutto, 1992), sweet tastes (Stefaruk \& van der Kooy, 1992, 1994), and sexual activity in the male (Everitt, 1990; Hughes, Everitt, \& Herbert, 1990) and in the female (Meisel \& Joppa, 1994; Meisel, Joppa, \& Rowe, 1996; Oldenburger, Everitt, \& de Jonge, 1992).

Despite the extensive use of the procedure it is unclear what is actually conditioned when natural rewards are used. It is generally considered that classical (Pavlovian) conditioning is involved (Tzschentke, 1998), but the responses studied (i.e., approach to and permanence in a particular environment) are instrumental. The classical conditioning taking place after a drug reward can be of the kind illustrated in Figure 1A. Here, the drug activates phys-

Part of these data were presented at the eighth annual meeting of the International Behavioral Neuroscience Society, Nancy, France, June 24 27, 1999. Correspondence should be addressed to A. Ågmo, Department of Psychology, University of Tromsø, N-9037 Tromsø, Norway (e-mail: andersa@psyk.uit.no). iological processes (presumably in some of the brain's reward systems) that generate the subjective state of positive affect. The physiological processes engendered or modified by the drug are considered as the unconditioned stimulus and the ensuing affective state as the unconditioned response. The conditioned stimulus may be any element or elements in the place environment. Through simultaneity this stimulus becomes associated with the affective state, and in the future it will be able to activate an affective reaction in the absence of the unconditioned stimulus. The affective reaction then activates the instrumental response of approach. The connection between the affective and instrumental responses can easily be explained either by Mowrer's (1947) two-factor theory of conditioning or by Bindra's $(1974,1978)$ model of incentive motivation.

When natural rewards are used instead of drugs, and when they are made available within the place preference environment, the conditioning process is more complex (Figure 1B). The unconditioned stimulus is certainly the natural reward itself (food, water, etc.) and the immediate unconditioned response is approach toward it. Direct contact with the reward stimulus will then activate the execution of consummatory behaviors, and these will be followed by a hedonic response, either because of the intrinsically rewarding properties of consummatory acts 
A

\begin{tabular}{|c|c|c|c|}
\hline \multirow[t]{2}{*}{$\begin{array}{l}\mathbf{U C S}_{1} \\
\text { Drug injection }\end{array}$} & $\begin{array}{l}\mathbf{U C S}_{2} \\
\begin{array}{l}\text { Physiological } \\
\text { reaction }\end{array}\end{array}$ & $\begin{array}{l}\text { UCR } \\
\text { Positive affect }\end{array}$ & \\
\hline & $\begin{array}{l}\text { CS } \\
\text { Cues in place } \\
\text { environment }\end{array}$ & $\begin{array}{l}\text { CR } \\
\text { Positive affect }\end{array}$ & $\begin{array}{l}\text { Instrumental response } \\
\text { Approach to } C S\end{array}$ \\
\hline
\end{tabular}

B

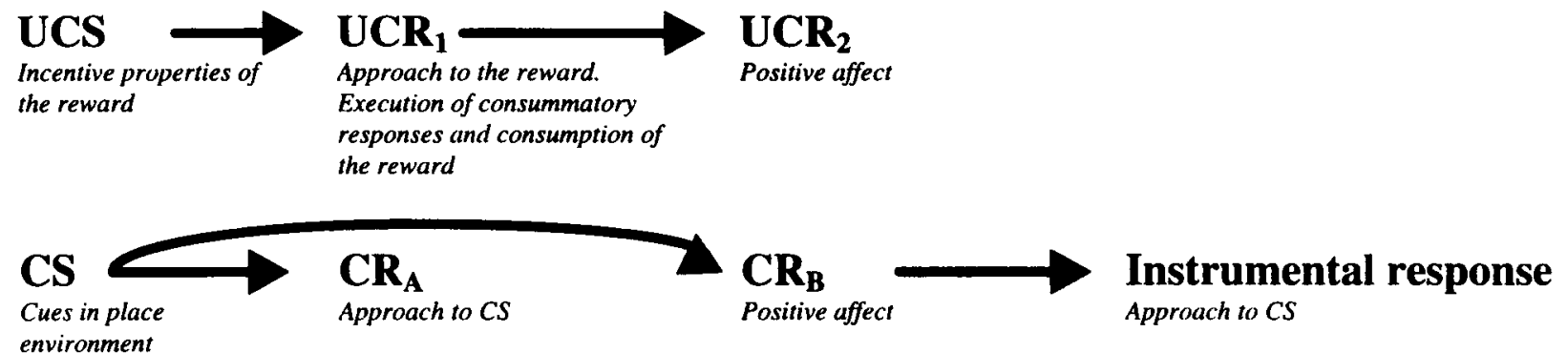
environment

Figure 1. The conditioning process leading to place preference when drug $(A)$ and natural $(B)$ rewards are used. UCS, unconditioned stimulus; UCR, unconditioned response; CS, conditioned stimulus; CR, conditioned response. For further details, see text.

or because of physiological reactions following consumption of the reward. In this situation two kinds of associations may become established-between the unconditioned incentive properties of the reward stimulus and environmental cues, on the one hand, and between the affective reaction associated either with consummatory behaviors or the effects of consumption and environmental cues, on the other. In both cases, the observable behavior at preference test will be approach, but the underlying processes are entirely different. Conditioned approach would be similar to "wanting," whereas a conditioned affective reaction would be similar to "liking" (Berridge, 1996; Berridge \& Robinson, 1998). As pointed out by these authors, the anatomical and neurochemical substrates for these processes are different. It may, therefore, be important to distinguish them.

The fact that animals learn to localize natural rewards (e.g., food, water, or a mate) and to approach them is well established; it is also well known that they will spend more time at places where natural rewards have been available than at places where they have not (e.g., Domjan, Lyons, North, \& Bruell, 1986; Elsmore \& McBride, 1994; Mellgren, 1983). Thus, if only the unconditioned approach behavior is what is becoming conditioned, then the place preference procedure would offer little new information as to the function of natural rewards. On the other hand, if the affective consequences of consummatory behaviors were associated to environmental cues, then the procedure would fulfill its original purpose as a means for analyzing the mechanisms of affect generation.

The purpose of the present experiment was to determine whether place conditioning with a natural reward involves simple approach behaviors to a place where reward has previously been available or whether the affective consequences of reward participates in conditioning. Food was used as an example of a natural reward, since there is much data available on learned approach behaviors to food. For example, it is well known that an animal rapidly learns to locate food sources using spatially distinctive stimuli (Baum, 1982; Kamil \& Yoerg, 1982). This is exactly what is provided in a typical place preference environment. Furthermore, when food is withdrawn from a place where it has previously been available, an initial reaction is an increased number of visits to it (Mellgren \& Elsmore, 1991; Mellgren \& Olson, 1983). Therefore, if only approach behaviors were conditioned, an increased number of visits to the rewarded compartment would be expected at test, when food is no longer available. On the other hand, affective consequences of feeding should be associated with the behavioral satiety sequence. As satiety is approached, and food-induced reward hence should be intense, behaviors typically displayed are grooming and resting (Antin, Gibbs, Holt, Young, \& Smith, 1975; Halford, Wanninayake, \& Blundell, 1998). These behaviors should be increased at the preference test if affective consequences of food consumption have been conditioned. 
A drug, morphine, was used as reward in other groups of animals. Since drug-induced place preference is, as mentioned, a result of the drug's affective consequences, it was used as a basis for comparisons with food-induced place preference. A detailed analysis of behavioral items recorded during conditioning and test was performed in order to determine whether behaviors displayed during conditioning were also present at test. This would give further clues as to the learning taking place during place preference conditioning.

\section{METHOD}

\section{Subjects}

C57BL/6 JICo mice originally obtained from Iffa Credo (L'Arbresle, France) were bred in the laboratory for several generations. They were housed 5 per cage under a reversed 12:12-h light:dark cycle, lights on at 2000$)$ at a constant temperature $\left(22^{\circ} \pm 1^{\circ} \mathrm{C}\right)$. Males were separated from females at weaning. Only males were used in the experiment. Commercial rodent pellets and water were freely available except for the days of place preference conditioning. At the beginning of the experiment, the animals were about 7 weeks old and weighed between 25 and $30 \mathrm{~g}$. The experiment was conducted in accordance with the Guide for Care and Use of Laboratory Animals as adopted and promulgated by the National Institutes of Health of the United States of America and in accordance with European Community Council Directive 86/609/EEC.

\section{Apparatus and Procedure}

Three-compartment place preference cages made of 9-mm plywood were used. All compartments were of equal size $(24 \times 20 \times$ $18.5 \mathrm{~cm}$ high). One lateral compartment was painted black and the floor was covered with sawdust, and the opposite compartment was painted white and the floor covered with transparent Plexiglas. The middle compartment was gray and communicated with each lateral compartment by diagonally opposed openings $(4 \times 4 \mathrm{~cm})$; that is, one opening was adjacent to the back wall while the other was adjacent to the front wall. A video camera connected to a videotape recorder was mounted $60 \mathrm{~cm}$ above the place preference cage. In order to avoid dead angles, the walls separating the lateral compartments from the middle one were inclined $15^{\circ}$ toward the center of the apparatus. All behavioral observations were made under dim white light (about 20 lux). Food was withdrawn from all subjects $24 \mathrm{~h}$ before the beginning of the experiment. During place preference conditioning, the subjects had access to food for $2 \mathrm{~h}$ per day, starting approximately $30 \mathrm{~min}$ after the end of the experimental session. Food deprivation continued until immediately after test. All sessions were performed between 1000 and $1400 \mathrm{~h}$.

Since food deprivation changes the motivational state of the animal, thereby affecting several behaviors, including locomotor activity (see, e.g., File \& Day, 1972), it was considered important to deprive all subjects of food. In that way, the only difference between the experimental groups was the rewarding event (food vs. morphine).

A 10-min pretest during which the subject was allowed to freely explore the entire apparatus was conducted to determine initial preference. The mouse was placed in the center of the middle compartmer: ${ }^{+}$, and each change of compartment was recorded on a handheld computer (Psion Organiser). A compartment change was considered to have occurred whenever a mouse moved its entire body from one compartment to another (i.e., the four paws were inside a compartment different from the previous one). Six conditioning sessions of $30 \mathrm{~min}$ each were then performed. During these sessions, the subject was confined to one of the lateral compartments. Three rewarded sessions alternated with three nonrewarded sessions. Ses- sions were performed daily from Monday to Saturday. The test, identical to the pretest, was performed $24 \mathrm{~h}$ after the last conditioning session. The following place preference data were used: time spent in each compartment, number of visits to each compartment, and mean duration of visits. In addition, the preference score (time in the rewarded compartment/[time in the rewarded compartment + time in the nonrewarded compartment]) was calculated. A significant increase in both parameters between pretest and test was the criterion for conditioned place preference. An increase in time spent in the rewarded compartment is by itself not sufficient for demonstrating preference conditioning. Time could be increased in the rewarded as well as the nonrewarded compartment simply because the middle compartment became less attractive. However, this would not modify the preference score. On the other hand, the preference score may increase because the subjects spend less time in the nonrewarded compartment and more in the middle compartment without any change in the time spent in the rewarded compartment. This would not indicate a conditioned place preference. Thus, both preference score and time spent in the rewarded compartment need to be modified. The use of this rather stringent criterion avoids spurious preferences.

Total locomotion was defined as the number of compartment changes during the session.

At all sessions, including pretest and test, the first $5 \mathrm{~min}$ in the place preference cage were recorded on videotape. The tapes were later analyzed and the frequency of the behaviors shown in Table 1 was recorded. All behavioral scoring was made by the same observer (T.S.). He was not blind to treatment condition, but due to the large number of behaviors observed and the absence of specific predictions of treatment effects, it seems unlikely that any consequential bias was introduced. The interrater reliability of the scoring is not known, but this is irrelevant since only 1 observer was used. Because the tapes were analyzed in random order and since all treatment conditions were represented on every tape, systematic variations in intrarater reliability were nonexistent. Therefore, a lack of reliability cannot account for the between-groups differences obtained.

\section{Design}

Six groups of 10 mice each were used. One group received an intraperitoneal saline injection ( $1 \mathrm{ml} / 100 \mathrm{~g}$ body weight) $3 \mathrm{~min}$ before both "rewarded" and nonrewarded sessions. A second group was intraperitoneally injected with morphine sulfate (Sigma), $3 \mathrm{mg} / \mathrm{kg}$, in a volume of $1 \mathrm{ml}$ saline $/ 100 \mathrm{~g}$ body weight $3 \mathrm{~min}$ before both rewarded and "nonrewarded" sessions. A third group was given the same dose of morphine at rewarded sessions and saline at nonrewarded sessions. The fourth group was not given any treatment at all during conditioning, while the fifth group had free access to food at both rewarded and "nonrewarded" sessions. Finally, the sixth group had free access to food only at rewarded sessions. Food reward consisted of a few pellets of the standard laboratory chow placed in the middle of the place conditioning compartment. On rewarded sessions the subjects were always placed in the white compartment. This was the initially nonpreferred compartment for all animals.

The reason for including groups rewarded in both compartments was to control for nonspecific or unconditioned effects of the rewards (see Discussion).

\section{Statistical Analyses}

It has been reported that the empirical distribution of place preference data frequently is positively skewed, making the assumption of a normal distribution unjustified. Parametric tests should not, therefore, be applied (Krauth, 1992). Therefore, data from test were compared with those from pretest within each of the six groups with Wilcoxon's matched-pairs signed-ranks test. An effect of a rewarding event was defined as a significant difference between pretest 
Table 1

Classification of Behavioral Items Used

in the Analyses of Factorial Correspondence

\begin{tabular}{|c|c|c|}
\hline Behavior Category & Subcategory & Qualification \\
\hline Sniffing & $\begin{array}{l}\text { Floor } \\
\text { Walls } \\
\text { Air }\end{array}$ & $\begin{array}{l}\text { Without locomotion } \\
\text { With lateral head movements } \\
\text { With vertical head movements } \\
\text { While moving }\end{array}$ \\
\hline \multicolumn{3}{|l|}{ Simple locomotion } \\
\hline Extended postures & $\begin{array}{l}\text { Simple } \\
\text { While sniffing floor } \\
\text { While sniffing walls } \\
\text { While sniffing air } \\
\text { While moving }\end{array}$ & \\
\hline Self-centered activities & $\begin{array}{l}\text { Scratching nose } \\
\text { Grooming } \\
\text { Licking } \\
\text { Scratching any part of } \\
\quad \text { body except nose }\end{array}$ & \\
\hline Rearing & $\begin{array}{l}\text { Without support } \\
\text { Without support and } \\
\text { moving front legs } \\
\text { With support of } \\
\text { front legs on wall } \\
\text { With support of front legs } \\
\text { on wall and moving } \\
\text { With support of front legs on } \\
\text { wall while walking with hind legs }\end{array}$ & $\begin{array}{l}\text { While sniffing air } \\
\text { While sniffing walls } \\
\text { With lateral head movements }\end{array}$ \\
\hline $\begin{array}{l}\text { Behaviors directed toward } \\
\text { sawdust }\end{array}$ & $\begin{array}{l}\text { Pushing forward (with front legs) } \\
\text { Pushing backward (with hind legs) }\end{array}$ & \\
\hline \multicolumn{3}{|l|}{ Vertical jumps } \\
\hline $\begin{array}{l}\text { Biting openings } \\
\text { Immobility }\end{array}$ & & \\
\hline
\end{tabular}

and test. Because six independent comparisons were performed on each variable, the Bonferroni correction was applied in order to protect significance levels. Thus, a nominal $p<.0083$ was required before a difference was considered significant at the .05 level. This criterion may be conservative, but has the advantage of reducing the probability of Type I error.

The frequency of the behavioral items recorded during pretest, conditioning, and test in the six groups was analyzed by the SPAD.T, a software package devoted to statistical analysis of lexical data, and SPAD.N, a program devoted to multifactorial data analysis (Lebart, Morineau, \& Becue, 1989; Lebart \& Salem, 1988). The programs first determine the frequency of each behavior, treating the behavioral items at each session as a series, and then build contingency tables (Lebart, Morineau, \& Piron, 1995). These tables consist of treatments as columns and behaviors as rows, the frequency of each behavior being at the crossing. The chi-square test is applied to each table in order to make sure that observed differences were significant. Briefly, the similarities between columns are determined by a chi-square criterion (column profile). In the same way, similarities between rows are determined (row profile; Lebart, Morineau, \& Warwick, 1984). These profiles are then subjected to a correspondence analysis in which the spaces containing the column points and the row points are projected on successive planes, defined by orthogonal axes or factors that intersect at the center of gravity of the point cloud. The first axis is the one that best explains the variance, the second the next best, and so on. The simultaneous representation of lines and columns allows for the determination of the coincidence between treatments and the relative frequency of specific behavioral items. Behavioral item points separated by small distances have closely similar distributions over treatments; the converse holds if they are separated by large distances. The same is true for treatment points. Behavioral items close to a given treatment have a relatively high frequency in this treatment group. For those unfamiliar with this analysis, several introductory texts are available (e.g., Greenacre, 1993; Greenacre \& Blasius, 1994).

All reported probabilities are two-tailed.

\section{RESULTS}

\section{Place Preference}

No effort to quantify the amount of food consumed was made. However, all food-rewarded mice ate almost continuously after a few minutes of exploration of the place preference compartment. It seems safe to maintain, then, that all subjects were indeed rewarded with food.

As expected, the time spent in the rewarded compartment as well as the preference score increased between 

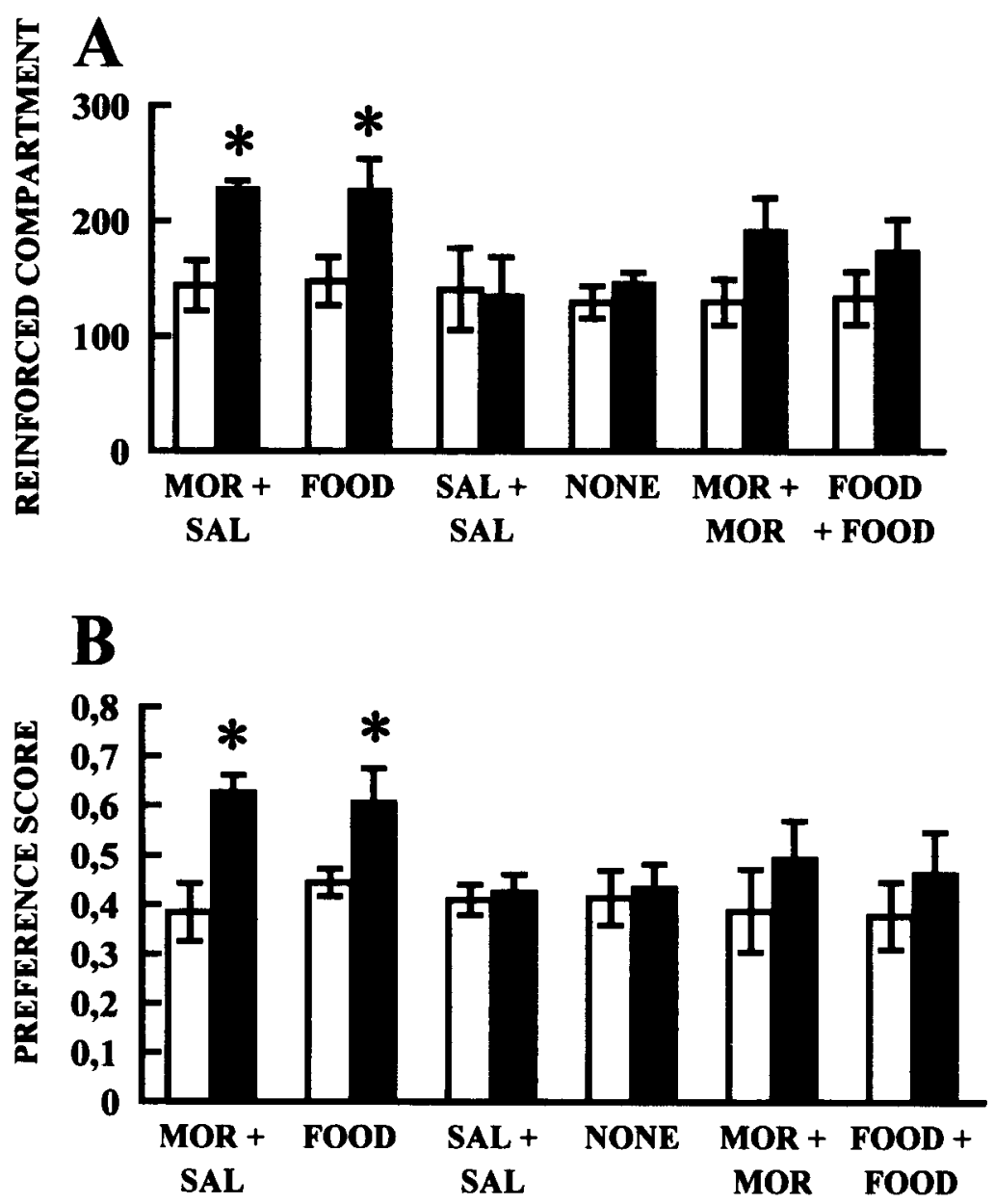

\section{REWARDING EVENT}

Figure 2. Time (in seconds) spent in the rewarded compartment (A) and preference score (B) at the preference pretest (open bars) and at test (black bars) in six groups of mice exposed to different rewards. MOR + SAL, morphine, $3 \mathrm{mg} / \mathrm{kg}$, at rewarded sessions and saline at nonrewarded sessions; FOOD, a few food pellets were present in the rewarded compartment only; SAL + SAL, saline at all sessions; NONE, no treatment; MOR + MOR, morphine, $3 \mathrm{mg} / \mathrm{kg}$, at all sessions; FOOD + FOOD, food was present in both place preference compartment. Data are medians and error bars represent the semi-interquartile range. There were 10 mice per group. "Different from pretest, $p<.05$.

pretest and test in mice rewarded with either morphine or food. No difference was found in the other groups. Data are shown in Figure 2.

When the mean duration of the visits to the rewarded compartment was analyzed, it was found that the animals treated with morphine increased the duration between pretest and test. There was no difference between pretest and test in the other groups. Mice rewarded with food in the nonpreferred compartment as well as animals given food in both compartments reduced the duration of visits to the nonrewarded compartment. Other treatments were ineffective. Data are shown in Figure 3.
As can be seen in Figure 4A, the frequency of visits to the rewarded compartment increased between pretest and test in animals rewarded with food in the white compartment and in the group given food in both compartments. Visits to the nonrewarded compartment were not modified (Figure 4B). It must be noted that the compartment labeled "nonrewarded" in Figure 4B was not so for the group given food in both compartments. In this group, the number of visits to it increased. Not surprisingly, total activity also increased in the group given food in both compartments. No effect was found in any other group (Figure 4C). 

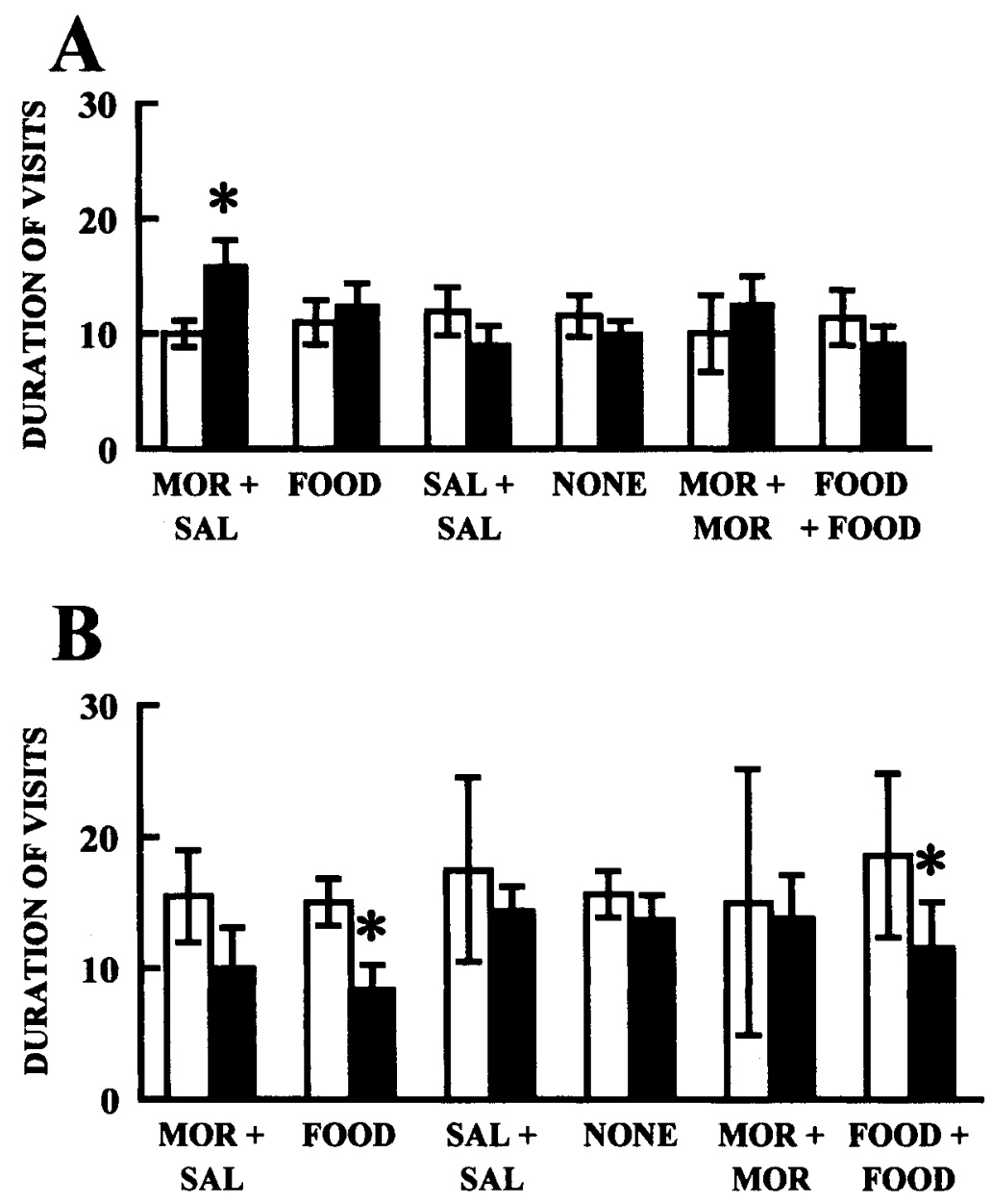

REWARDING EVENT

Figure 3. Mean duration of visits (in seconds) to the rewarded (A) and nonrewarded compartments (B) at pretest (open bars) and at test (black bars) in six groups of mice exposed to different rewards. For further details, see Figure 2 legend.

\section{Behavioral Items}

Behaviors directed toward food were not recorded, although they were important in the food-rewarded groups. However, since such behaviors were not possible in the other groups, simply because no food was present, they could not be included in comparisons of different rewards. Furthermore, at pretest and test, food was absent for all groups. It is important to note that behaviors directed toward food were not abundant during the first few minutes of the conditioning sessions, and that it was the first $5 \mathrm{~min}$ that were analyzed. Indeed, all groups displayed mainly exploratory or investigatory behaviors during these $5 \mathrm{~min}$. Thus, all groups are comparable, although the environment was not identical in food-rewarded groups and in groups rewarded with morphine.
Behavior in the presence of the reward (conditioning). To analyze possible modifications of behavior over the three conditioning sessions, a factorial analysis of correspondence was performed for the three rewarded sessions for the groups rewarded with morphine and food in the nonpreferred compartment. The table was built with the six cases as columns (two groups with three sessions each) and the behavioral items as rows. Three factors accounted for $93.3 \%$ of the variance. The third axis accounted for only $5.6 \%$ of the total variance, and was therefore ignored. As can be seen in Figure 5, the two groups are clearly opposed on the first axis. The group rewarded with morphine is on positive coordinates and is characterized by numerous sniffing and licking movements. The three sessions of the food-rewarded group are on the op- 

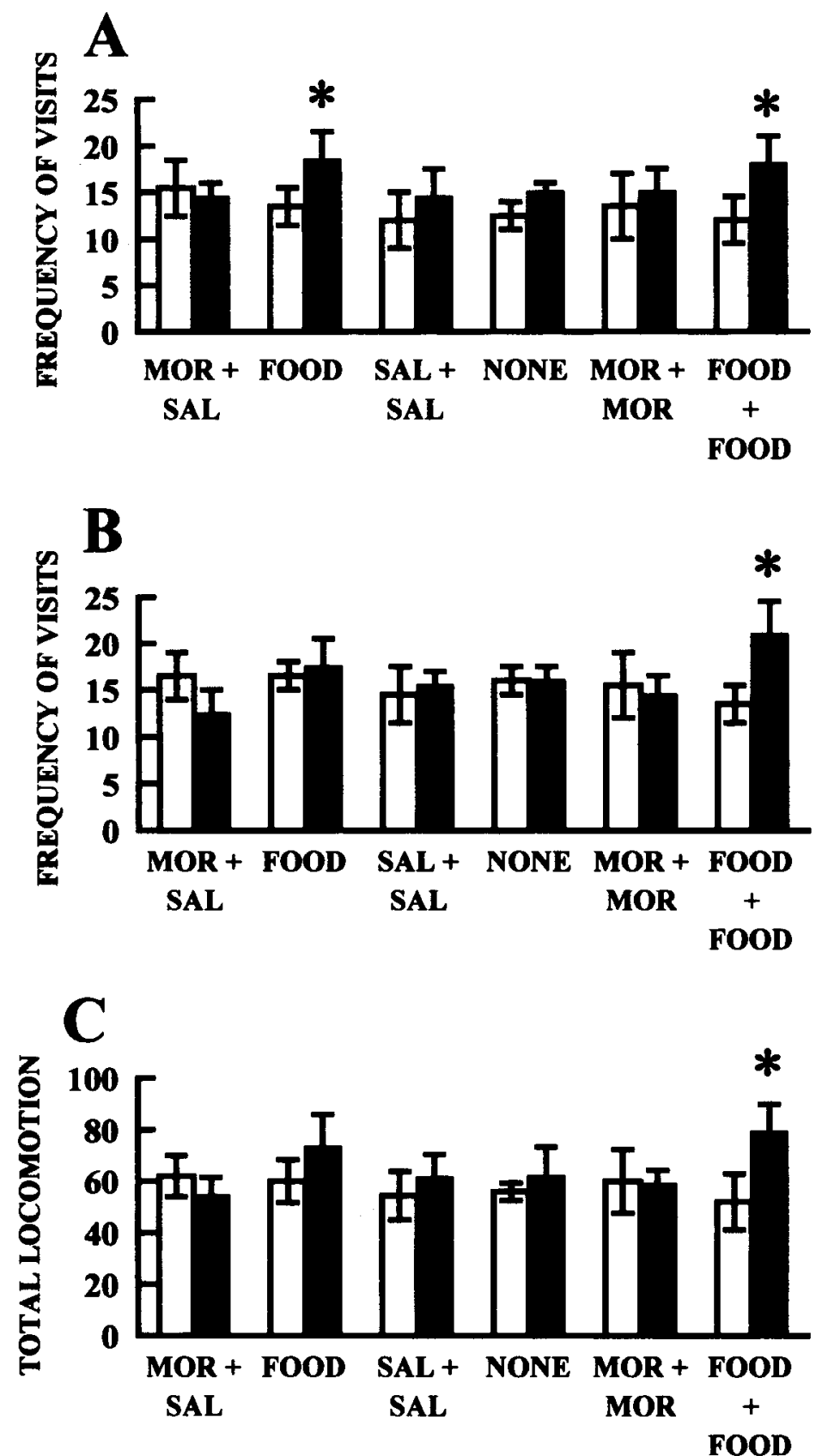

\section{REWARDING EVENT}

Figure 4. Number of visits to rewarded $(A)$ and nonrewarded $(B)$ compartments as well as total locomotion at pretest (open bars) and test (black bars) in six groups of mice given different rewards. For further details, see Figure 2 legend.

posite side, characterized by a low frequency of licking and abundant extended postures.

Differences between sessions were very large in the food-rewarded group and can be seen on the second factor. The first session was different from the two others, being characterized by extended postures. This suggests that results obtained at Session I were mainly due to novelty. Food was then present for the first time. The third session was characterized by rearing with support while sniffing the air and moving. In the group rewarded with 


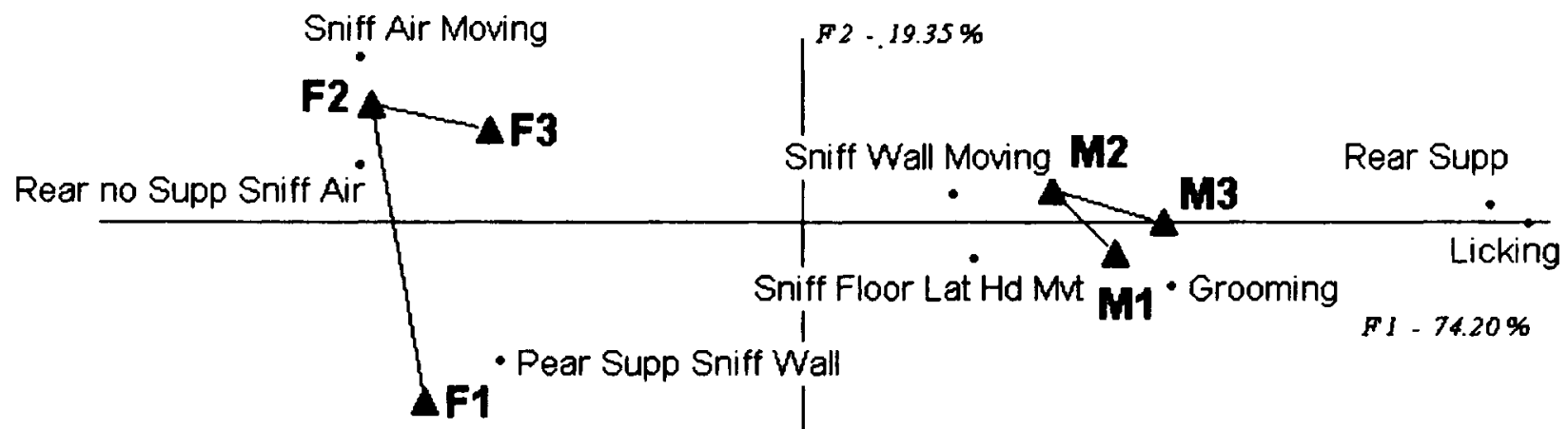

- Ext Post Moving

- Ext Post

Figure 5. Factorial analysis of correspondence factor plane for the comparison of the groups rewarded with food (F) and morphine (M) in the white compartment at each of the three rewarded conditioning sessions. The numbers following the letters indicate the conditioning session (1-3). Points indicate the exact position of the behavioral items. Only the behaviors that were most characteristic for each group are shown. Abbreviations are self-explanatory if Table 1 is considered.

morphine, although differences between sessions were of lower amplitude, they showed a very similar pattern on both the first and second factors.

In order to illustrate the relationship between relative frequencies of the behavioral items and the results of the correspondence analyses, the relative frequencies of the behaviors included in Figure 5 at each of the three conditioning sessions for the morphine- and food-rewarded groups are shown in Figure 6. As can easily be seen, the behaviors shown to characterize the group rewarded with morphine according to the correspondence analysis are those with a frequency above the median in this group and far below the median in the food-rewarded group. Similarly, behaviors characteristic of the food-rewarded group are displayed with a high frequency in this group and with a low frequency in the group rewarded with morphine. Interestingly, food-typical behaviors are found to the left on the horizontal axis in Figure 5, whereas morphine-typical behaviors are found to the right. Thus, this axis could be said to represent reward. If we compare the three conditioning sessions within the group treated with morphine in Figure 6, it can be observed that the frequency of the behaviors remained quite stable over sessions. To the contrary, the frequencies of characteristic behaviors in the food-rewarded group changed much from Session 1 to Session 2, and little from Session 2 to Session 3 . In Figure 5, this is illustrated by the fact that the morphine group remained at about the same position over the three conditioning sessions, whereas there was a big distance between Sessions 1 and 2 on the vertical axis in the food-rewarded group. The vertical axis can, therefore, be said to represent conditioning sessions. This example should make it evident that the correspondence analysis provides more information than frequency tables associated with a chi-square test. In the following, we will show only data from the correspondence analyses.

Behavior in the absence of the reward (test): 1. Comparison of rewards. Here, behaviors were analyzed independently of the compartment in which they occurred to determine how the rewards had modified behavior in general at test.

In order to evaluate the effects of morphine, a factorial analysis of correspondence was performed in which only the groups treated with morphine (in the rewarded compartment and in both compartments) and the appropriate control were included. Since there were only three groups, two factors accounted for the total variance. The first axis opposed the group rewarded with morphine in the white compartment only to the other two groups. The morphinerewarded group was characterized by sniffing the walls and the floor (with lateral head movements), while the other two groups were characterized by rearing while sniffing the air or sniffing the walls with lateral head movements. On the second axis, the group given morphine in the white compartment only was intermediate between control and the group injected with morphine at all ses- 

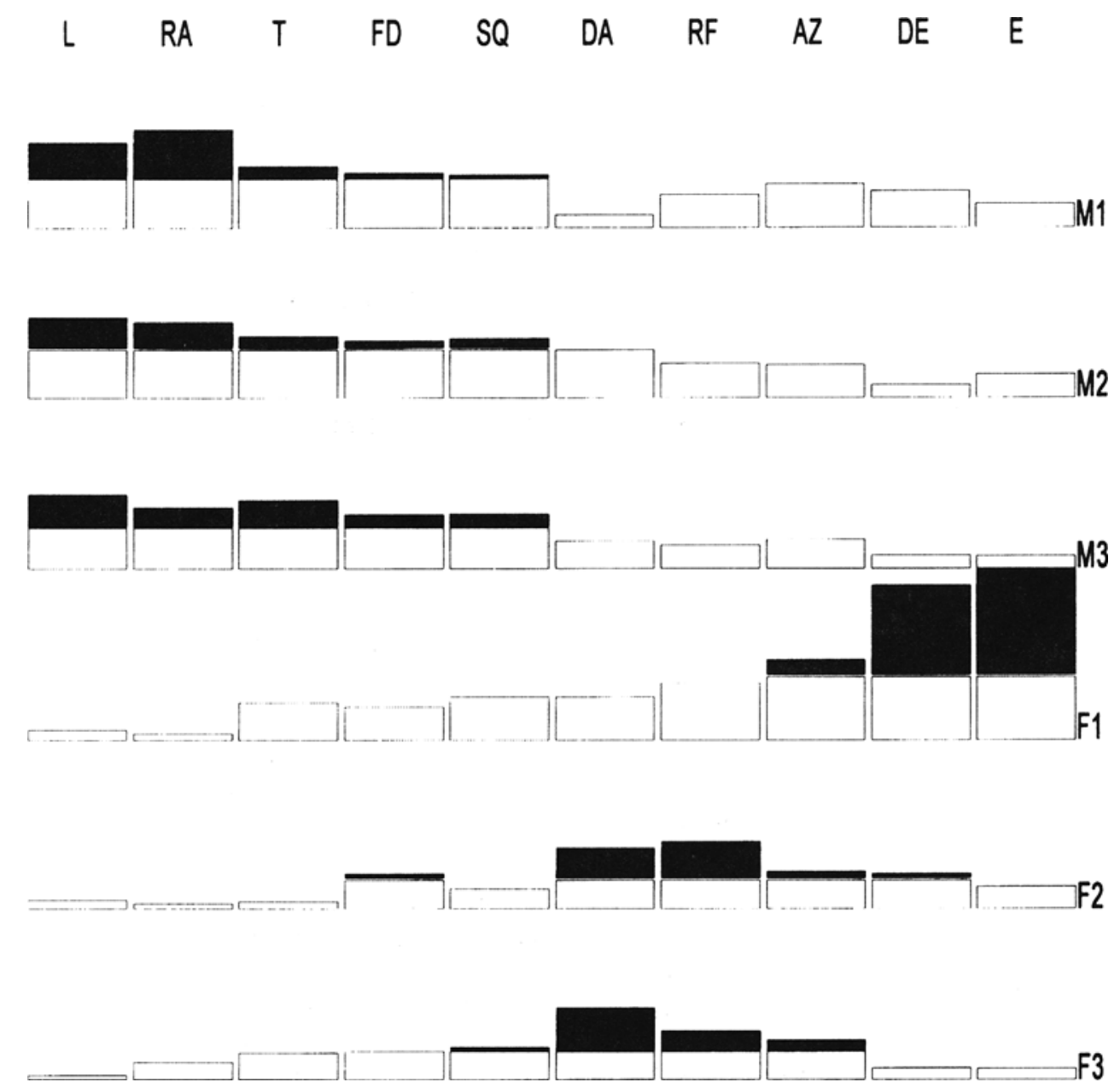

Figure 6. Relative frequency of behavioral items characterizing the groups rewarded with morphine (M1-M3) or food (FI-F3) in the white compartment only. The numbers indicate conditioning session. The black part of each bar shows scores above the median of the row. L, licking; $R A$, rearing with support; $T$, grooming; FD, sniffing the wall while moving; SQ, sniffing the floor with lateral head movements; DA, sniffing the air while moving; $R F$, rearing without support while sniffing the air; $A Z$, rearing with support while sniffing the wall; DE, extended posture while moving; $E$, extended posture.

sions. The latter group displayed particularly self-centered behaviors like scratching and grooming, while the control group was distinguished by a high frequency of sniffing the air and walls without moving and of extended postures with locomotion (Figure 7).

The effects of food reward were then evaluated in a factorial analysis of correspondence including the foodrewarded groups and their appropriate controls. Again, two factors accounted for the total variance. The group rewarded with food on all sessions is located to the right on the first axis, whereas the other groups are found somewhat to the left of origin of coordinates. The second axis opposes the controls to the group rewarded with food in the white compartment, with the group given food in both compartments intermediate between the two. The animals given food in both compartments displayed many vertical jumps and rearing with support while moving. The group given food in the white compartment only was characterized by rearing with support while sniffing the walls. Controls displayed much rearing with support and sniffing the air with or without rearing with support. Results are shown in Figure 8.

Food reward was then compared with morphine reward in a factorial analysis of correspondence including the groups rewarded with morphine or food in the white compartment and their controls (animals injected with saline or left untreated, respectively). The first factor distinguishes the rewarded groups from their controls. Both control groups are found to the right on this axis, whereas the rewarded groups are located somewhat to the left of the origin of coordinates. Behaviors typical of the group rewarded with morphine are sniffing the floor or the walls 


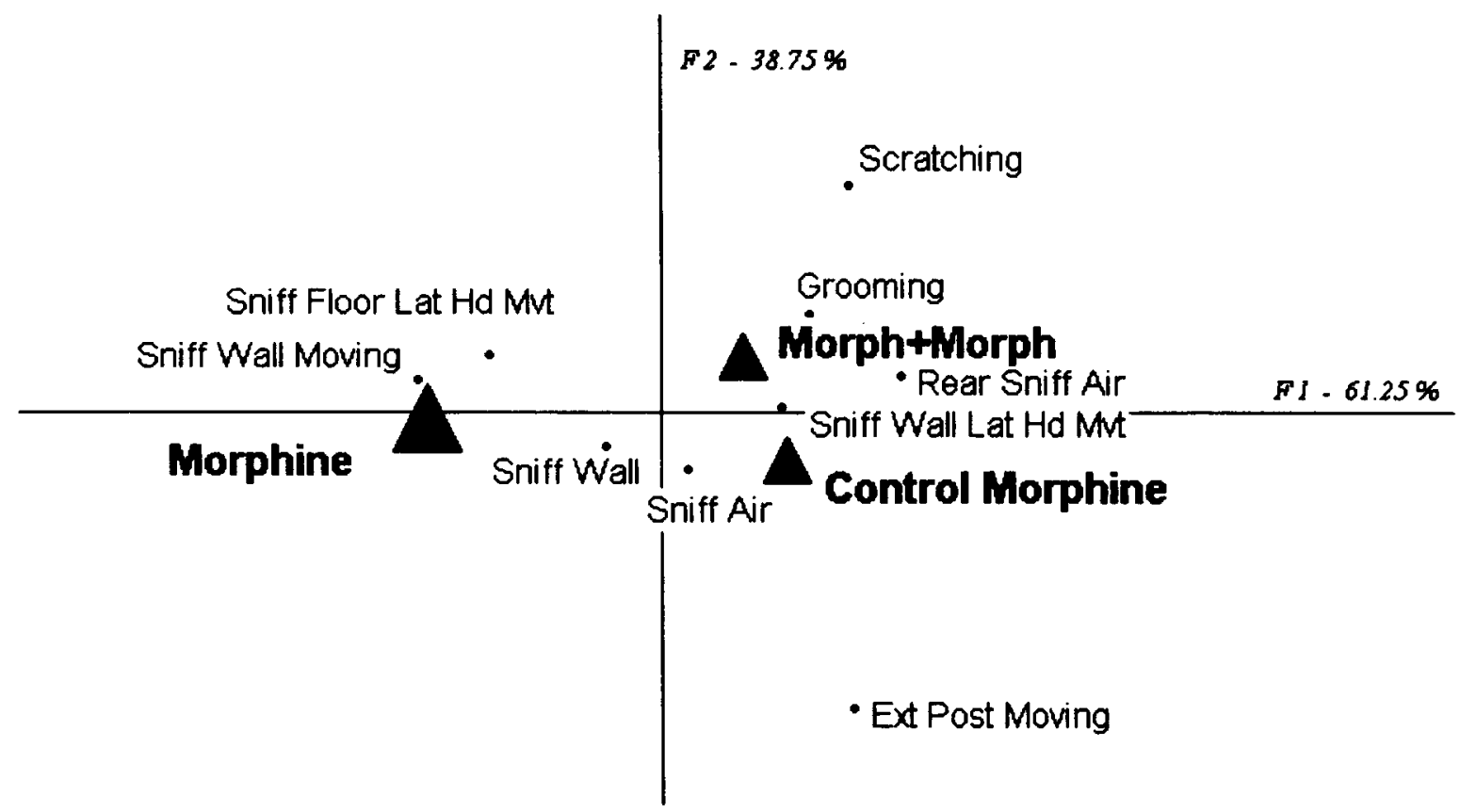

Figure 7. Factorial analysis of correspondence factor plane for the comparison of the groups rewarded with morphine in the white compartment and rewarded with morphine in both lateral compartments, and the control group injected with saline at all sessions. For additional details, see Figure 5 legend.

while moving, whereas controls displayed much sniffing the floor and the air and rearing while sniffing the air. The second axis opposes the group rewarded with food to the group rewarded with morphine. The food-rewarded group was characterized by rearing with support while sniffing the walls and moving. The two control groups are not clearly separated on this second axis and are characterized by sniffing the air (Figure 9 ).

Taken together, the factorial analyses of correspondence show that the rewarded groups displayed a large amount of sniffing the wall and floor. The controls displayed mostly sniffing of the air. The main difference between the groups rewarded with food and morphine in the white compartment is that the former displayed a lot of rearing while sniffing the walls while the latter group rarely displayed rearing. It is also noteworthy that the group rewarded with morphine in the white compartment showed more self-centered behaviors. These behaviors were even more frequent in the group rewarded with morphine in both compartments. The group given food in both compartments displayed many vertical jumps, a behavior that was almost absent in the other groups. When behavior at test was compared with that during conditioning, it was found that many of the behaviors that increased in frequency throughout conditioning continued to be important at test, when the reward was no longer present. The behavior of rearing while moving increased during conditioning in the food-rewarded group, while sniffing the floor while moving or sniffing the floor with lateral head movements and sniffing the wall increased in the morphine-rewarded group.
Behavior in the absence of reward (test): 2 . Comparison of compartments. In order to further analyze the effects of the rewards and the associations between reinforcing event and environment that become established during conditioning, the behaviors within each of the three compartments were analyzed for each of the six groups at test. Factorial analysis of correspondence compared the rewarded, neutral, and nonrewarded compartments. Since there were only three categories, two factors accounted for the total variance.

When data from the morphine-treated group were analyzed, the first factor opposed the nonrewarded to the neutral compartment, with the rewarded compartment being intermediate. Nonreward was distinguished by sniffing the air with locomotion and rearing with support while sniffing the air. In the middle compartment, rearing without support and sniffing the walls or the floor without locomotion were characteristic. The second factor opposed the rewarded compartment to the nonrewarded. The former was characterized by sniffing the floor or the walls while moving and the latter by rearing with support while sniffing the air and moving. Results are illustrated in Figure 10A.

The animals rewarded with food were then analyzed. The first factor opposed the rewarded compartment to the nonrewarded. The former was characterized by sniffing the walls while moving and the latter compartment was distinguished by rearing with support while sniffing the walls. The second factor opposed the neutral to both lateral compartments. The neutral compartment was characterized by sniffing the floor with lateral head 


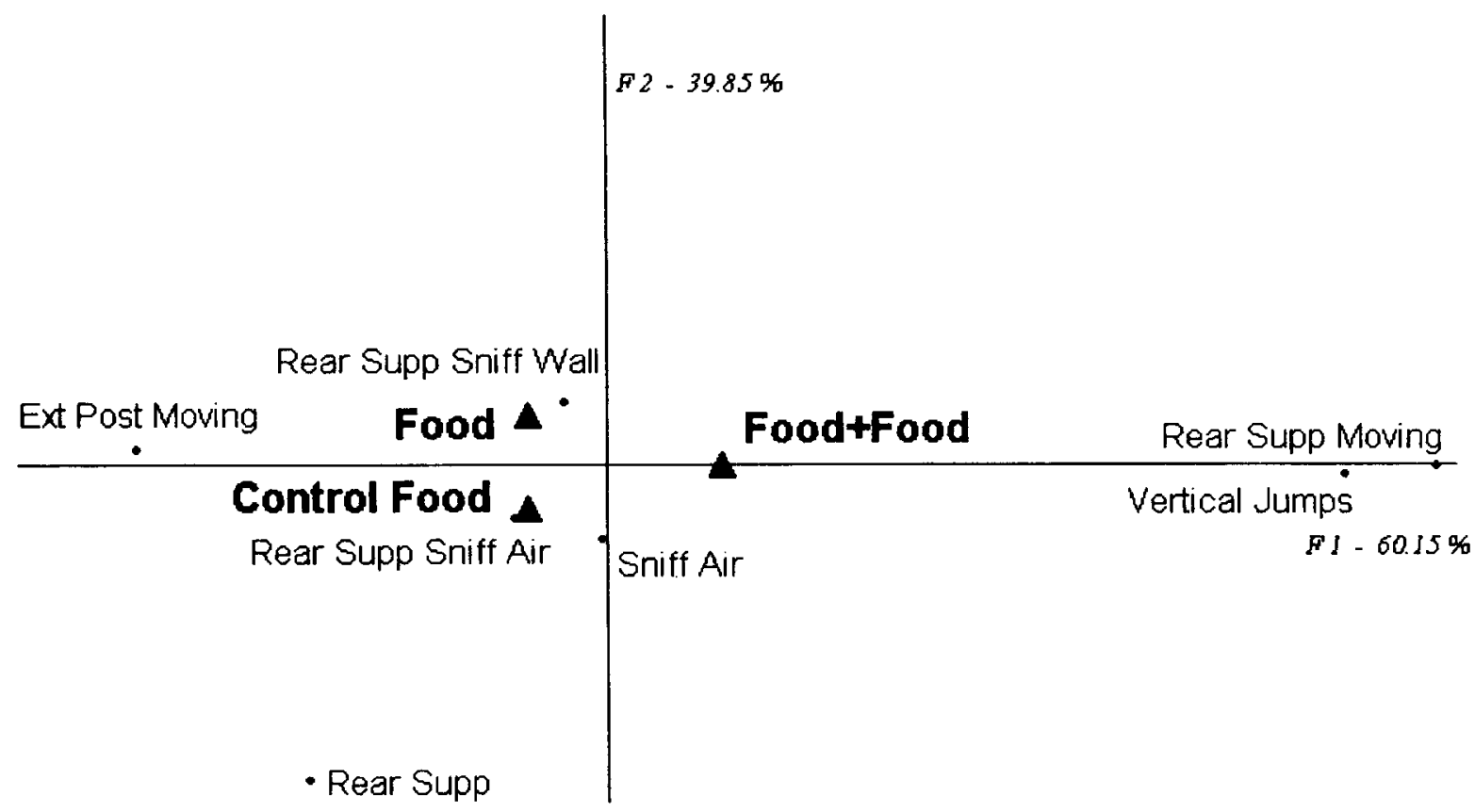

Figure 8. Factorial analysis of correspondence factor plane for the comparison of the groups rewarded with food in the white compartment and rewarded with food in both lateral compartments, and the control group that was never rewarded. For additional details, see Figure 5 legend.

movements and by rearing while sniffing the walls. The rewarded compartment was distinguished by sniffing the walls without moving (Figure 10B).

Similar analyses were also performed for the other four groups (saline-injected controls, controls, morphine before every conditioning session, food in both lateral compartments). These analyses showed that behaviors in the middle compartment were similar in all groups, and that there were only minor differences between the white and black compartments in these groups. However, the animals treated with morphine at all sessions displayed self-centered behaviors in addition to those common to the other groups. The behaviors typical of the rewarded groups (for morphine, sniffing the floor or the walls while moving, always without rearing, and for food, rearing while sniffing the walls and moving and sniffing the floor while moving) were observed mostly in the rewarded compartment. This would suggest that these behaviors are, in fact, a consequence of reward.

\section{DISCUSSION}

Morphine, $3 \mathrm{mg} / \mathrm{kg}$, produced a conditioned place preference in the $\mathrm{C} 57 \mathrm{BL} / 6$ mice, in agreement with earlier studies in this and other mouse strains (Semenova, Kuzmin, \& Zvartau, 1995) and in rats (Barr, Paredes, \& Bridger, 1985; Blander, Hunt, Blair, \& Amit, 1984; Mucha, van der Kooy, O'Shaugnessy, \& Bucenieks, 1982). Food reward also produced a clear-cut place preference. The capacity of this reward to induce place preference has not previously been tested in the mouse, but it has been reported to be effective in rats (Bechara \& van der Kooy, 1992; Nader \& van der Kooy, 1994; Papp, 1988, 1989; Spyraki et al., 1982).

It is generally assumed that morphine's capacity to induce positive affect is the basis for the place preference produced by it. Furthermore, positive affect is believed to influence behavior in a similar way, independently of its origin. Therefore, if the affective consequences of food consumption were the main element participating in conditioning, then food and morphine would be expected to affect behavior in a similar way. However, this does not seem to be the case. In addition to increasing the time spent in the rewarded compartment and the preference score, morphine enhanced the mean duration of visits. Thus, the drug's effect consists in making the subjects stay in contact with the stimuli present during conditioning for a longer period of time upon each visit. A similar observation has been made in rats treated with morphine and amphetamine (Parker, 1992; Vezina \& Stewart, 1987). Food reward, to the contrary, increased the number of visits to the rewarded compartment without changing the mean duration. This means that animals rewarded with food increased the time spent in the rewarded compartment and the preference score because of a larger number of visits. Notably, animals rewarded with food in both compartments increased their number of visits to both compartments, while those rewarded only in the white compartment increased their visits specifically to that one. This fact reinforces the idea that approach behaviors had 


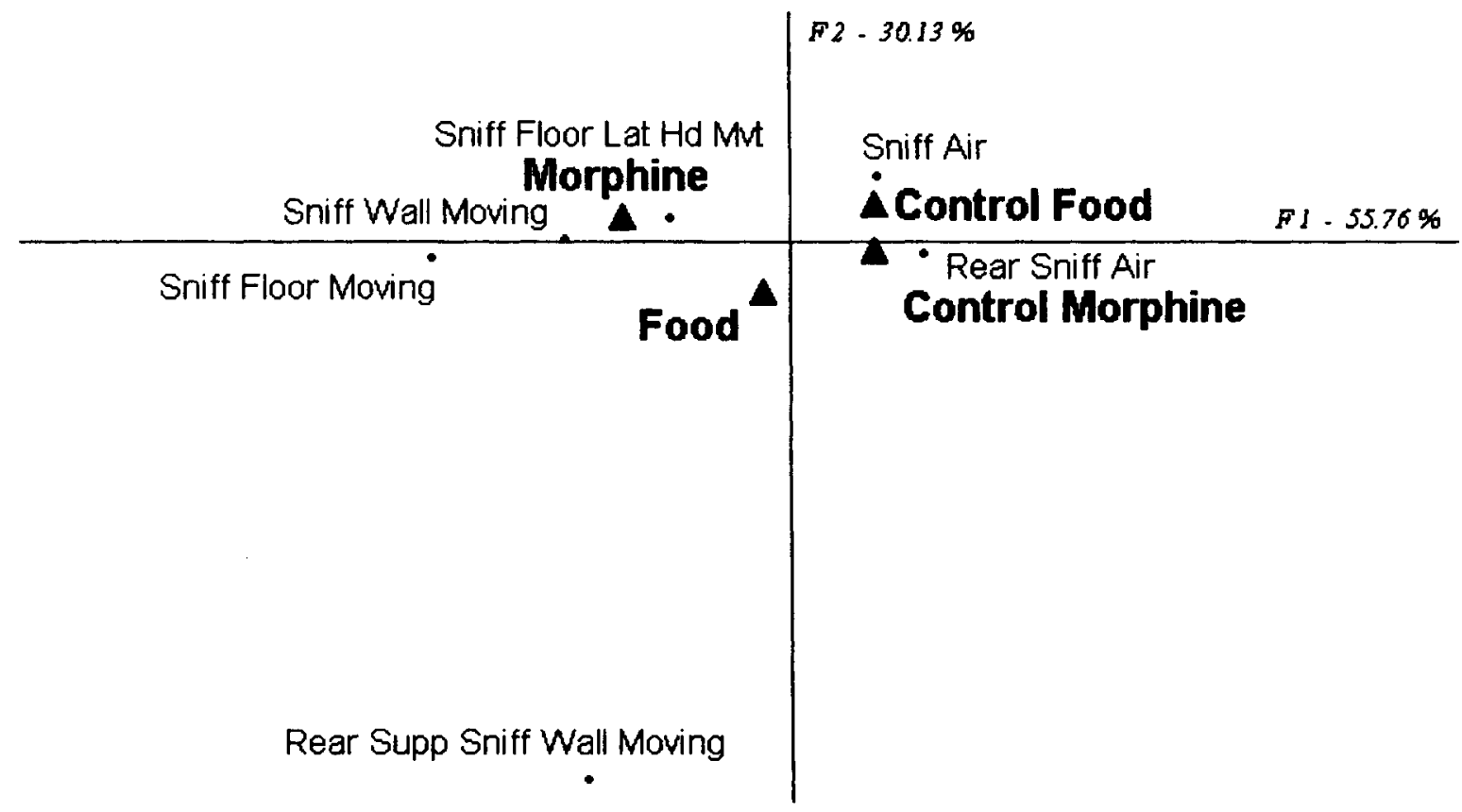

Figure 9. Factorial analysis of correspondence factor plane comparing the groups rewarded with either food or morphine in the white compartment only with their respective controls at test. For additional details, see Figure 5 legend.

been conditioned. An increased number of visits to a site where food has been previously present is predicted by foraging theory (Mellgren \& Brown, 1987; Mellgren \& Elsmore, 1991; Mellgren \& Olson, 1983) and suggests that the unconditioned approach behaviors activated by food had become conditioned rather than the affective consequences of its consumption. Moreover, there was no increase in grooming and resting, as would have been expected if the affective consequences of food had been conditioned. As noted, these behaviors increase as satiety is approached. Thus, we need to conclude that the place preference observed after food reward is mainly unrelated to the affective consequences of feeding.

As mentioned in the Method section, a biased place preference procedure was employed in these experiments. This means that one compartment was systematically preferred over the other one, and that the nonpreferred compartment was rewarded for all subjects. The main reason for this was to ensure that the physical characteristics of the rewarded compartment were identical for all animals. It has sometimes been argued that a place preference in this procedure does not necessarily reflect increased preference caused by positive affect. It could also be a result of reduced aversion (see, e.g., Schechter \& Calcagnetti, 1993; Tzschentke, 1998). Hence, the biased procedure would be unsuitable for the analysis of positive hedonic effects. However, reduction of the aversive properties of a situation is rewarding and can therefore be expected to produce positive affect. The question of whether place preference is produced by reduced aversion or not would, then, be quite irrelevant. Furthermore, drugs and natural rewards have generally similar effects in biased and unbiased procedures (Schechter \& Calcagnetti, 1993, 1998; Tzschentke, 1998). It seems safe to conclude that the effects of morphine in the present study indeed are a consequence of drug-induced positive affect.

The detailed analyses of behaviors displayed during conditioning show that food and morphine reward have quite different behavioral consequences. In fact, a factorial analysis of correspondence established that the factor separating rewards accounted for $74.2 \%$ of the variance. This should be compared with the factor separating conditioning session, which accounted for only $19.35 \%$ of the variance. Thus, type of reward is a far more important determinant of behavior than is the degree of conditioning. This notion is supported by the fact that the difference between conditioning sessions was much larger in the food-rewarded group. There, the first session was located far away from the second and third, suggesting that the novelty of the food pellets determined behaviors associated with the axis representing conditioning session more than did the effects of conditioning per se. For example, extended postures observed in the food-rewarded groups load heavily on this factor. These postures are frequently considered typical components of exploratory behaviors or a standard reaction to novelty (Misslin \& Ropartz, 1981). It seems, then, that an animal's behavior during place preference conditioning was largely determined by the intrinsic effects of the reward, present already at the first conditioning session. The putative establishment of associations between these intrinsic effects and environmental cues does not seem to have any large 

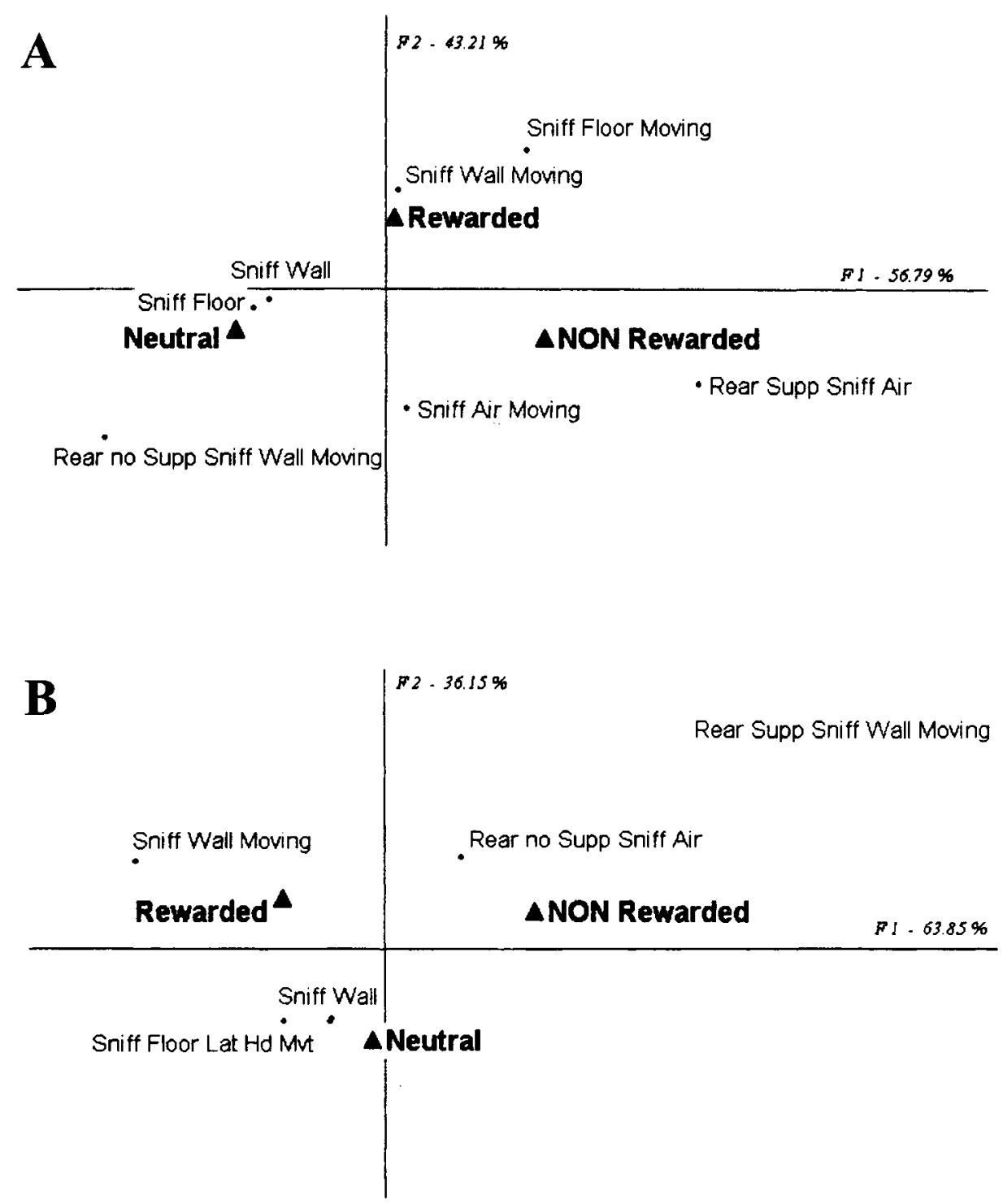

Figure 10. Factorial analysis of correspondence factor plane comparing the three compartments in the group rewarded with morphine $(A)$ or food $(B)$ in the white compartment only. For additional details, see Figure 5 legend.

influence on behavior. This seems quite logical. Conditioned stimuli should have minimal effects when the unconditioned stimulus is also present.

At test, that is, in the absence of the rewarding event, the group rewarded with morphine was different from its controls on both axes obtained in the factorial analysis of correspondence. The behaviors displayed by the former group were similar to those displayed during conditioning. This would suggest that effects of morphine actually have become associated to environmental cues. Moreover, when the three compartments of the place preference cage were compared, it was found that behaviors in the rewarded (white) compartment were different from those in the neutral (gray) or nonrewarded (black) com- partments. This, however, might have been due to the different floor texture in the compartments, and thus does not constitute convincing evidence. Nevertheless, the fact that the compartments did not differ at pretest (data not shown) suggests that reward is an important determinant of the difference obtained at test. The behaviors typical of the morphine-rewarded group are sniffing the walls or the floor. Rearing is rare. Interestingly, the walls and the floor constitute the discriminative stimuli that allow for a distinction between reward and nonreward during conditioning. It is, therefore, most likely that the affective state induced by morphine has been associated with these stimuli, and that at test, through conditioning, they are able to activate a fraction of the unconditioned affec- 
tive response. The animals try to remain close to these stimuli in order to maximize the affective state. Although speculative, this proposal nicely explains why the animals rewarded with morphine make longer visits to the rewarded compartment.

Food reward also affected behavior at test. Here, only one axis differentiated between the group given food in the white compartment and its two controls. Behaviors typical of food reward were different kinds of rearing and sniffing. The group given food in both lateral compartments distinguished itself by performing vertical jumps, a behavior almost nonexistent in the other groups. Sniffing and rearing are typical of exploration, and vertical jumps are typical of escape. It is quite possible that the behavior of the food-rewarded group at test is strongly determined by search for the absent food or escape from a frustrating situation.

It must be noted that all groups were food deprived at test. Thus, any conditioned "hunger drive" that could have been activated in the animals rewarded with food would have been of marginal importance in addition to the unconditioned "hunger" already present. Furthermore, although stimuli associated with feeding during food deprivation can induce eating in sated rats (Weingarten, 1983), there is little evidence that a "hunger drive" can be conditioned to contextual cues (Cravens \& Renner, 1970; Mineka, 1975). In view of these arguments, it is unlikely that conditioned "hunger" could account for the behaviors characteristic of the food-rewarded mice.

One alternative explanation for the differences between food- and morphine-rewarded animals is a difference of reward magnitude. It has been reported that rats stay longer at places where a large reward has been obtained than at places where a smaller reward was available (Gallistel, 1994). Thus, if food reward were of less magnitude than morphine reward, the results obtained in the present experiment could be entirely explained by this. However, examination of the place preference data suggests that the two rewards were of similar magnitude. Both the time spent in the rewarded compartment and the preference score were in fact not different between these rewards (Figure 2 ). It has been shown that these variables indeed are sensitive to reward magnitude (Bardo, Rowlett, $\&$ Harris, 1995). Furthermore, there are data showing that the effects of reward magnitude are mainly on asymptotic strength of associations (Couvillon \& Bitterman, 1993; Couvillon, Lee, \& Bitterman, 1991). It is not evident that the three rewarded conditioning trials employed in the present studies were sufficient for the establishment of asymptotic strength of associations. Therefore, it is not likely that the differences between food and morphine reward observed here can be attributed to different reward magnitude.

The results from the factorial analyses of correspondence coincide with the place preference data in the way that they indicate that morphine and food reward have different effects, and that conditioning with food reward only marginally if at all includes affective consequences of feeding. Other explanations for the difference between food and morphine reward are improbable. This means that place preference conditioning with natural rewards present in the place environment is conceptually different from preference conditioning with drugs. Furthermore, the information obtained in studies with natural reward is quite trivial. Place preference conditioning seems to be a convoluted way to confirm that animals can learn to localize rewards in space.

It is, however, possible to perform place preference conditioning with natural rewards in such a way that the procedure remains a technique for studying affective consequences of reward. Natural rewards can be administered just before place preference conditioning in the same way as drugs are always administered before. When this procedure is used, a natural reward is made accessible in a setting different from the place environment. In this case, approach to the reward and consumption of it cannot be associated to cues in the place environment. Only the affective consequences are present when the animal is transferred to the place preference apparatus. Conditioning then becomes identical to what is shown in Figure $1 \mathrm{~A}$. The drug is simply replaced by a natural reward. This procedure has been used for analyzing reward produced by water ( $\AA$ gmo, Federman, Navarro, Padua, \& Velázquez, 1993), sweet solutions ( $̊$ gmo, Galván, \& Talamantes, 1995; Ågmo \& Marroquín, 1997) and sexual activity in males (Ågmo \& Berenfeld, 1990; Ågmo \& Gómez, 1993) and females (Frye, Bayon, Pursnani, \& Purdy, 1998; Paredes \& Alonso, 1997).

It could be argued that the difference between the procedures for place preference conditioning with natural rewards is trivial. However, there are data showing that results obtained with the two procedures are not identical. For example, place preference obtained with sexual reward in the male is unaffected by administration of the opiate antagonist naloxone when copulation occurs within the place environment (Everitt, 1990), but is completely blocked when copulation occurs immediately before place conditioning ( $\AA$ gmo \& Berenfeld, 1990). Saccharine is unable to produce place preference when consumed just before conditioning ( $\AA$ gmo \& Marroquín, 1997), but is efficient when made accessible within the place environment (Stefaruk \& van der Kooy, 1992, 1994). These data suggest that different mechanisms are implicated in the two conditioning procedures. This may have important implications for the study of natural rewards with place preference conditioning.

\section{REFERENCES}

Ågmo, A., \& Berenfeld, R. (1990). Reinforcing properties of ejaculation in the male rat: Role of opioids and dopamine. Behavioral Neuroscience, 104, 177-182.

Ågmo, A., Federman, I., Navarro, V., Padua, M., \& Velázquez, G. 
(1993). Reward and reinforcement produced by drinking water: Role of opioids and dopamine receptor subtypes. Pharmacology, Biochemistry \& Behavior, 46, 183-194.

Ågmo, A., Galván, A., \& Talamantes, B. (1995). Reward and reinforcement produced by drinking sucrose: Two processes that may depend on different neurotransmitters. Pharmacology. Biochemistry \& Behavior, 52, 403-414.

Ågmo, A., \& Gómez, M. (1993). Sexual reinforcement is blocked by infusion of naloxone into the medial preoptic area. Behavioral Neuroscience, 107, 812-818.

ÅGMO, A., \& MARROQuín, E. (1997). Role of gustatory and postingestive actions of sweeteners in the generation of positive affect as evaluated by place preference conditioning. Appetite, 29, 269-289.

Antin, J., Gibis, J., Holt, J., Young, R. C., \& Smith, G. P. (1975). Cholecystokinin elicits the complete behavioral sequence of satiety in rats. Journal of Comparative \& Physiological Psychology, 89. 748-760.

Bardo, M. T., Rowlett, J. K., \& Harris, M. J. (1995). Conditioned place preference using opiate and stimulant drugs: A meta-analysis. Neuroscience \& Biobehavioral Reviews, 19, 39-51.

Barr, G. A.. Paredes, W., \& Bridger, W. H. (1985). Place conditioning with morphine and phencyclidine: Dose dependent effects. Life Sciences, 36, 363-368.

BAUM, W. M. (1982). Choice, changeover and travel. Journal of the Experimental Analysis of Behavior, 38, 35-49.

BECHARA, A., \& VAN DER KOOY, D. (1992). A single brain substrate mediates the motivational effects of both opiates and food in nondeprived, but not in deprived animals. Behavioral Neuroscience, 106. $351-363$

BERRIDGE, K. C. (1996). Food reward: Brain substrates of wanting and liking. Neuroscience \& Biobehavioral Reviews, 20, 1-25.

Berridge, K. C.. \& Robinson, T. E. (1998). What is the role of dopamine in reward: Hedonic impact, reward learning, or incentive salience? Brain Research Reviews, 28, 309-369.

BindRA, D. (1974). A motivational view of learning, performance, and behavior modification. Psvchological Review, 81, 199-213.

BINDRA, D. (1978). How adaptive behavior is produced: A perceptualmotivational alternative to response reinforcement. Behavioral \& Brain Sciences, 1, 41-52.

Blander, A., Hunt, T., Blair, R., \& Amit. Z. (1984). Conditioned place preference: An evaluation of morphine's positive reinforcing properties. Psychopharmacology, 84, 124-127.

Couvillon. P. A., \& BitTerman, M. E. (1993). Learning in honeybees as a function of amount of reward: Further experiments with color. Animal Learning \& Behavior, 21, 23-28.

Couvillon, P. A., Lee, Y. L., \& Bitterman, M. E. (1991). Learning in honeybees as a function of amount of reward: Rejection of the equalasymptote assumption. Animal Learning \& Behavior, 19, 381-387.

Cravens, R. W., \& RenNer, K. E. (1970). Conditioned appetitive drive states: Empirical evidence and theoretical status. Psychological Bulletin, 73, 212-220.

Crowder, W. F., \& Hutto, C. W. (1992). Operant place conditioning measures examined using two nondrug reinforcers. Pharmacology, Biochemistry \& Behavior, 41, 817-824.

Domjan, M., Lyons, R., North, N. C., \& Bruell, J. (1986). Sexual Pavlovian conditioned approach behavior in male Japanese quail (Coturnix coturnix japonica). Journal of Comparative Psychology, $100,413-421$.

Elsmore, T. F., \& MCBride, S. A. (1994). An eight-alternative concurrent schedule: Foraging in a radial maze. Journal of the Experimental Analysis of Behavior, 61, 331-348.

Everitt, B. J. (1990). Sexual motivation: A neural and behavioral analysis of the mechanisms underlying appetitive and copulatory responses of male rats. Neuroscience \& Biobehavioral Reviews, 14. 217-232.

FILE. S. E., \& DAY, S. (1972). Effects of time of day and food deprivation on exploratory activity in the rat. Animal Behaviour, 20, 758762.

Frye, C. A., Bayon, L. E., Pursnani, N. K., \& Purdy, R. H. (1998).
The neurosteroids, progesterone and $3 \alpha, 5 \alpha$-THP, enhance sexual motivation, receptivity, and proceptivity in female rats. Brain Research, $808,72-83$.

GALLISTEL, C. R. (1994). Foraging for brain stimulation: Toward a neurobiology of computation. Cognition, 50, 151-170.

Greenacre, M. J. (1993). Correspondence analysis in practice. San Diego: Academic Press.

Greenacre, M. J., \& Blasius, J. (1994). Correspondence analysis in the social sciences. San Diego: Academic Press.

Hal Ford, J. C. G., WanNinayake, S. C. D., \& Blundell, J. E. (1998) Behavioral satiety sequence (BSS) for the diagnosis of drug action on food intake. Pharmacology, Biochemistry \& Behavior, 61, 159-168.

Hughes, A. M., Everitt, B. J., \& Herbert, J. (1990). Comparative effects of preoptic area infusions of opioid peptides, lesions and castration on sexual behaviour in male rats: Studies of instrumental behaviour, conditioned place preference and partner preference. Psychopharmacology, 102, 243-256.

KAMIL, A. C., \& YOERG, S. J. (1982). Learning and foraging behavior In P. P. G. Bateson \& P. H. Klopfer (Eds.), Perspectives in ethology (Vol. 5, pp. 325-364). New York: Plenum.

KRAUTH, J. (1992). Parametric analysis of sojourn times in conditioned place preference experiments. Journal of Neuroscience Methods, $\mathbf{4 2}$, 219-227.

Lebart. L., Morineau, A., \& Becue, M. (1989). Système portable pour l'analyse des donnees textuelles [Portable system for the analysis of lexical data]. Saint Mandé, France: CISIA.

Lebart, L., Morineau, A., \& Piron, M. (1995). Statistique exploratoire multidimensionelle [Multidimensional exploratory statistics]. Paris: Dunod.

Lebart, L., Morineau, A., \& Warwick, K. M. (1984). Multivariate descriptive statistical analysis. New York: Wiley.

LEBART, L., \& SAlEM, A. (1988). L'analyse statistique des données textuelles [Statistical analysis of lexical data]. Paris: Dunod.

MEISEL, R. L., \& JOPPA, M. A. (1994). Conditioned place preference in female hamsters following aggressive or sexual encounters. Physiol ogy \& Behavior, 56, $1115-1118$.

Meisel, R. L., Joppa, M. A., \& Rowe, R. K. (1996). Dopamine receptor antagonists attenuate conditioned place preference following sexual behavior in female Syrian hamsters. European Journal of Pharmacology, 309, 21-24.

Mellgren, R. L. (1983). Animal cognition and behavior. Amsterdam: North-Holland.

MELlgReN, R. L., \& BROWN, S. W. (1987). Environmental constraints on optimal-foraging behavior. In M. L. Commons, A. Kacelnik, \& S. J. Shettleworth (Eds.), Foraging (pp. 133-151). Hillsdale, NJ: Erlbaum.

Mellgren, R. L., \& Elsmore, T. F. (1991). Extinction of operant behavior: An analysis based on foraging considerations. Animal Learning \& Behavior, 19, 317-325.

MELlgRen, R. L., \& OLSON, M. W. (1983). Mazes, Skinner boxes, and feeding behavior. In R. L. Mellgren (Ed.), Animal cognition and behavior (pp. 223-252). Amsterdam: North-Holland.

MinekA, S. (1975). Some new perspectives on conditioned hunger. Journal of Experimental Psychology: Animal Behavior Processes, 1 , 134-148.

Misslin, R., \& Ropartz, P. (1981). Responses of mice to a novel object. Behaviour, 78, 169-177.

MOWRER, O. H. (1947). On the dual nature of learning: A reinterpretation of "conditioning" and "problem-solving." Harvard Educational Review, 17, 102-148.

Mucha, R. F., van der Kooy, D.. O'Shaugnessy, M., \& Bucenieks, P. (1982). Drug reinforcement studied by the use of place conditioning in the rat. Brain Research, 243, 91-105.

NADER, K., \& VAN DER KOOY, D. (1994). The motivation produced by morphine and food is isomorphic: Approaches to specific motivational stimuli are learned. Psychobiology, 22, 68-76.

Oldenburger, W. P., Everitt, B. J., \& de Jonge, F. H. (1992). Conditioned place preference induced by sexual interaction in female rats. Hormones \& Behavior, 26, 214-228. 
PAPP, M. (1988). Different effects of short- and long-term treatment with imipramine on the apomorphine- and food-induced place preference conditioning in rats. Pharmacology, Biochemistry \& Behavior, 30, 889-893.

PAPP, M. (1989). Differential effect of short- and long-term antidepressant treatments on the food-induced place preference conditioning in rats. Behavioural Pharmacology, 1, 69-74.

Paredes, R. G., \& Alonso, A. (1997). Sexual behavior regulated (paced) by the female induces conditioned place preference. Behavioral Neuroscience, 111, 123-128.

PARKER, L. A. (1992). Place conditioning in a three- or four-choice apparatus: Role of stimulus novelty in drug-induced place conditioning. Behavioral Neuroscience, 106, 294-306.

Perks, S. M., \& Clifton, P. G. (1997). Reinforcer revaluation and conditioned place preference. Physiology \& Behavior, 61, 1-5.

Rossi, N. A., \& REID, L. D. (1976). Affective states associated with morphine injections. Physiological Psychology, 4, 269-274.

Schechter, M. D., \& Calcagnetti, D. J. (1993). Trends in place preference conditioning with a cross-indexed bibliography, 1957-1991. Neuroscience \& Biobehavioral Reviews, 17, 21-41.

Schechter, M. D., \& CalcagnetTi, D. J. (1998). Continued trends in the conditioned place preference literature from 1992 to 1996 , inclusive, with a cross-indexed bibliography. Neuroscience \& Biobehavioral Reviews, 22, 827-846.

Semenova, S., Kuzmin, A., \& Zvartau, E. (1995). Strain differences in the analgesic and reinforcing action of morphine in mice. Pharmacology, Biochemistry \& Behavior, 50, 17-21.

Spyraki, C., Fibiger, H. C., \& Phillips, A. G. (1982). Attenuation by haloperidol of place preference conditioning using food reinforcement. Psychopharmacology, 77, 379-382.

STEFARUK, T. L., \& VAN DER KOOY, D. (1992). Saccharin's rewarding, conditioned reinforcing, and memory-improving properties: Mediation by isomorphic or independent processes. Behavioral Neuroscience, 106, 125-139.

Stefaruk, T. L., \& VAN Der KoOY, D. (1994). Tegmental pedunculopontine lesions in rats decrease saccharin's rewarding effects but not its memory-improving effect. Behavioral Neuroscience, 108, 972980.

Tzschentke, T. M. (1998). Measuring reward with the conditioned place preference paradigm: A comprehensive review of drug effects, recent progress and new issues. Progress in Neurobiology, 56, 613672.

Vezina, P., \& Stewart, J. (1987). Conditioned locomotion and place preference elicited by tactile cues paired exclusively with morphine in an open field. Psychopharmacology, 91, 375-380.

WeINGARTEN, H. P. (1983). Conditioned cues elicit feeding in sated rats: A role for learning in meal initiation. Science, 220, 431-433.

(Manuscript received August 31, 1999; revision accepted for publication December 3, 1999.) 